\title{
Quantification and Analysis of Offensive Situations in Different Formats of Sided Games In Soccer
}

\author{
by \\ Jorge Diaz-Cidoncha Garcia 1,2, Ignacio Refoyo Román 2, Julio Calleja-González³, \\ Alexandre Dellal ${ }^{4,5}$
}

\begin{abstract}
There has been a lot of research that enabled soccer to improve: its technique, tactics and strategy through analysis and training. Nevertheless, players' need to interact with each other turns any defending or attacking situation into complex solutions with a wide range of variables to be considered, in which the player is never isolated and must make the move that has the most positive impact on play. Fifty-four sided games played in three different formats (5v5, $7 v 7$ and 9v9) and with two age groups (U9 and U14) were filmed at three soccer clubs in Spain in order to identify the most relevant attacking moves, from a technical and tactical perspective. This study used the observational method; it is descriptive and is applied through well-prepared systematic quantitative observation in a natural environment. A key part of the method involved viewing the match recordings and logging moves that had been categorised beforehand. Cohen's Kappa analysis showed that the results for the most representative variables presented a substantial degree of concordance (0.61-0.80). The results show that there were significant variations depending on the game format, and the following study will present a description and analysis of the aspects that had considerable influence on attacking moves in different formats of sided games (5v5, $7 v 7$ and 9v9). The study also presents various practical applications for the area of training and analysing both youth and professional soccer.
\end{abstract}

Key words: game format; soccer; attacking move; technique; tactics.

\section{Introduction}

Over the course of the past decade, playing soccer in reduced spaces has become particularly important, both for organised or spontaneous set-ups (Castellano et al., 2008). This type of play offers a great deal of possibilities and combinations and gives participants an increased level of interaction in the game (McGarry et al., 2002). Sided games (SG) are very beneficial for players, particularly during learning stages of grassroots and youth football (Castellano et al., 2011) and for training senior players. By SG we mean $5 \mathrm{v} 5,7 \mathrm{v} 7$ and $9 \mathrm{v} 9$ formats using the goal or not. Consequently, the pitch dimensions are smaller than in an 11v11 format and the rules are adapted to each format (e.g. the goals and the boxes are smaller). The study and analysis of match situations, particularly those where players interact with each other, are of great importance in that they identify the factors that influence correct decision making which may lead to success in the game of football (Gréhaigne et al., 2011). This undertaking requires a particularly

\footnotetext{
1 - Fédération Internationale de Football Association (FIFA) / Education and Technical Development Department.

2 - National Institute of Physical Education (INEF), Polytechnic University of Madrid / Sports Department.

3 - National Institute of Physical Education (INEF), University of Basque Country.

4 - FIFA Medical Excellence Centre, Santy Orthopedicae clinical, sport science and research department, Lyon, France.

5 - Unité de recherche de l'OGC Nice (soccer), Nice, France.
} 
complex implementation due to a large number of variables that are influential in a single team play. All players (both from the team itself and the opposing team) directly impact the final result of play, depending on what they do and the decisions they make.

There are several aspects which give rise to this complexity in the analysis of small-sided games: a high number of players involved in the development of play, interactive nature of the players' moves, a degree of evolution and the "internal logic" of soccer, a high number of direct and indirect performance factors and the pitch size determined from the competition itself. Experience (Di Salvo et al., 2009; Kelly and Drust, 2008) has shown that players get more touches of the ball, learn quicker and take more decisions during the game (player concentration increases because the ball is never far away). There will also be a greater degree of participation as there are fewer players on the pitch and therefore increased individual attention from the participants is guaranteed. It is worth noting that because players are continually exposed in SG, there will be more attacking and defending situations. FIFA (2012) presents statistics to explain some of the differences among various small-sided formats, enabling us to compare the number of moves that take place during a play: players touch the ball five times more often in 4-a-side soccer and 50\% more in 7-a-side soccer; players are three times more often in one-against-one situations in 4-aside soccer and twice as often in 7-a-side; goals are scored every two minutes in 4-a-side soccer on average and every 4 minutes in 7-a-side; goalkeepers are involved in the action two to four times more often in 7-a-side soccer than in 11-aside soccer; and, the ball is out of play $8 \%$ of the time in 4 -a-side soccer, $14 \%$ in 7 -a-side and $34 \%$ in 11-a-side soccer.

\section{Tactical and strategic moves in football in reduced spaces}

For this study a move is understood as a significant combination, more or less complex, of various motor and mental processes, which are indispensable to solve a problem arising from a game situation. Tactics are characterised as an intelligent combination of motor resources, individual and collective, to solve game situations as they occur as a result of the competitive activity itself, and also as the decisions, taken before the game, on the choice and order of moves. Strategy shows how to set up opportunities that should be exploited tactically (Gabbet and Mulvey, 2008).

\section{Material and Methods}

\section{Participants}

A cross section study consisting of fiftyfour grassroots soccer games from the U-9 and U14 age male groups was conducted. The physical characteristics of the players were as follows: for U-9, body height $134.1 \pm 12.3 \mathrm{~cm}$; body mass $29.4 \pm$ $11.6 \mathrm{~kg}$ and for U-14, body height $163.0 \pm 13.8 \mathrm{~cm}$; body mass $52.9 \pm 13.1 \mathrm{~kg}$ ); it is remarkable that there are no recent studies that compared the variables of this study for the U-9 and U-14 age groups. The same teams were monitored for a specific period of time to ensure that the cross section was as broad as possible. Furthermore, all of the formats $(5 \mathrm{v} 5,7 \mathrm{v} 7$ and $9 \mathrm{v} 9)$ were considered when selecting the cross section. The games were recorded at three different clubs: the football academy of the RFEF (Spanish Football Association), Adarve-Barrio del Pilar and Villanueva del Pardillo (all of them playing in the first or second state youth leagues). Of the 54 games in the cross section, the following recordings (and subsequent analyses) were made: 18 in each club (RFEF, Adarve and Villanueva del Pardillo), 18 on each playing surface (natural turf, artificial turf, soil), 18 in each format $(5 \mathrm{v} 5,7 \mathrm{v} 7$, $9 \mathrm{v} 9), 36$ for each age group (U-9 and U-14). Each game lasted 20 minutes, with no breaks and no substitutions. A cross section with high representativeness and which covers all of the possible parameters that influence the development of the game was chosen. The Madrid Polytechnic University's Institutional Review Board approved the use of human subjects in this research for the purpose of collecting the data and statistically analysing it, according to the declaration of Helsinki.

\section{Equipment - instruments}

The equipment used for organising the SG consisted of balls (size 4 for U-9 and size 5 for U14), different coloured bibs, cones and markers, mini goals and seven-a-side goals (depending on the game format). The games were timed using a Traceable digital stopwatch. The pitch measurements were $20 \times 30 \mathrm{~m}$ for $5 \mathrm{v} 5,30 \times 45 \mathrm{~m}$ for $7 \mathrm{v} 7$ and $45 \times 60 \mathrm{~m}$ for $9 \mathrm{v} 9$. The games were recorded using a Sony HDR-CX570 camera and a 
HI-POD tripod, which were acquired by the FIFA's Education and Technical Development Department and can continue to be used for this study in the next coming months, should this be necessary. The games were watched and analysed on a TV monitor once all of the scheduled sessions had been recorded and categorised properly. Each player had a pitch radio of $4.8 \mathrm{~m}$ for $5 \mathrm{v} 5,6.4 \mathrm{~m}$ for $7 \mathrm{v} 7$ and $5.5 \mathrm{~m}$ for $9 \mathrm{v} 9$.

\section{Measures}

There are currently very few studies that reflect the tactical and technical differences among various formats of SG $(5 \mathrm{v} 5,7 \mathrm{v} 7$ and $9 \mathrm{v} 9)$ and different playing surfaces. For this reason, technical and tactical variables were recorded for each of the games analysed and then compared against each other so as to reflect their main characteristics and the differences among them. Therefore, just one team within a club and in the same age group was monitored so that the players and teams analysed would be the same and the nature of the study would not vary from one recording to the next. Furthermore, an initial assessment was applied before each game to ensure that the conditions relating to size and quality of the playing field, climate, and support facilities for the AV recording, etc. were acceptable; external conditions were standardized (24ํํㄹ external temperature, $60 \%$ humidity).

\section{Procedures}

The videos of the 54 games used for this study were recorded on the soccer pitch. All of the games were watched on site and then analysed from the recordings, with the same process being followed at all times, which was carried out by a minimum of three different reviewers. The data was collected as the recordings were watched, with previously defined variables being monitored. The study was conducted using the observational method; it is a descriptive study and was carried out by way of observation that was systematised, prepared beforehand, carried out in a natural setting and of a quantitative nature. The observational method was applied as follows: formulation of a problem, collection and recording of data, analysis and interpretation of the observed data and communication of the results.

\section{Statistical Analyses}

After applying a normality test, the arithmetic average of each and every variable previously recorded from the footage of the 54 games was calculated. For the percentage variables (time and pitch zones), the percentages for each of them were compared. A Pearson's chisquared test was performed with a level of significance (Pearson's X2<.05). Cohen's Kappa has been analysed for the variables of the ball out play, touches per game and attempts at goal. Standard deviations were also calculated in every figure. SPSS 22.0 (Chicago, Illinois, USA) pack was used for every statistic calculation.

\section{Results}

The averages of all variables are presented below as well as the percentages for the ball being out of play and for play in a specific half of the pitch (attacking or defensive). All of the results are arranged according to the game format, age group and club from which they were collected. Figure 1 gives an overall summary of all of the values for each age group and game format. Significant differences can be noted in case of the number of touches for the players per game, including goalkeepers.

The results in Figure 2 show that the total number of touches per game (263 for U-9 and 253 for U-14) as well as the average number of touches per outfield player (62 and 56 for each age group, respectively) were significantly higher in $5 \mathrm{v} 5$ format than in the other game formats. The same for touches in the defensive and attacking halves, where high values were recorded in both halves (142.5 touches of the ball in the defensive half and 115.5 in the attacking half); the distribution of touches was similar, where values close to $50 \%$ were recorded in both: attacking half and the defensive half. The results also show that the total number of attempts at scoring was higher in the $5 \mathrm{v} 5$ format ( 13 for U-9 and 8 for U-14, with $67 \%$ on target). The number of times the ball entered the penalty area and the attempted dribbles also shows that there were more attacking moves in the $5 \mathrm{v} 5$ format, with the ball penetrating the area 17 times and 13 attempted dribbles in the U-9 age group. The number of attempted passes - both successful and unsuccessful - was also higher in the $5 \mathrm{v} 5$ format, where $75 \%$ and $86 \%$ of the passes were successful for the U-9 and U-14 age groups, respectively. In comparison with the other formats, the 
goalkeepers showed higher values in all moves recorded in the $5 \mathrm{v} 5$ format, with a total average of 17 touches, 5 saves, 5.5 kicks, 3 throws and 5.5 goal kicks per match.

Figure 3 shows that the ball was out of play longer in the $7 \mathrm{v} 7$ format, where it was stopped for $38 \%$ of the time in the U-9 age group and $32 \%$ of the time in the U-14. Despite being lower than in the $5 \mathrm{v} 5$ format, the number of touches among the outfield players in the $7 \mathrm{v} 7$ format was higher than in the 9v9 format (average of 33 and 39 touches for each age group, respectively). The number of touches in the defensive half was higher in $7 \mathrm{v} 7$ than in the other two formats and accounted for $56 \%$ of the touches in the U-9s and $51 \%$ in the U14s. However, the number of touches in the attacking half was lower than in the other two formats ( $44 \%$ and $49 \%$, respectively). Seen against the total number of attempted passes, unsuccessful passes were also quite high, accounting for $30 \%$ of the attempted passes in the U-9 age group and $17 \%$ in the U-14s.

As shown in Figure 4, the ball was out of play for a considerable amount of time in the $9 \mathrm{v} 9$ format, specifically $35 \%$ of the time in the U-9 age group and $32 \%$ of the time in the U-14s. The total number of touches per match was high, reaching a total of 278 touches in the U-14s. Of all formats, however, the average number of touches per outfield player was lowest in the $9 \mathrm{v} 9$ format (29 touches per player per match). The ball was in play in both halves of the pitch for an almost equal amount of time, with $50.5 \%$ of the actions of play being recorded for the defensive half and $49.5 \%$ for the attacking half. The number of offtarget shots was highest in the 9v9 format, where 396 off-target shots were recorded in the U-9 age group and $35 \%$ of the shots were off target in the U-14s. The figures recorded for the attacking play in $9 \mathrm{v} 9$ were similar to those in the $7 \mathrm{v} 7$ format and significantly lower than in $5 \mathrm{v} 5$. The goalkeepers also participated less in the play in $9 \mathrm{v} 9$ than in the other two formats and had a total of 7.5 touches per game, 2 saves, 3 kicks and 0.5 goal kicks per game.

The results of the chi-squared test performed on the technical and tactical variables collected during the games are also considered in this study. A level of significance of alpha 0.005 was chosen and the associated table value for $\chi^{2}$ to two degrees of freedom and alpha 0.05 was therefore 5.99. The hypothesis stated that the frequency of moves depended the on game format. Therefore, given that there were three different formats, one third of the moves was expected to occur in each format (5v5, 7v7 and 9v9). Given that the probability was lower than alpha (the values were on the left in the goodness of the fit chart), it could be concluded that the hypothesis was correct and that the frequency of the moves would therefore depend on game format.

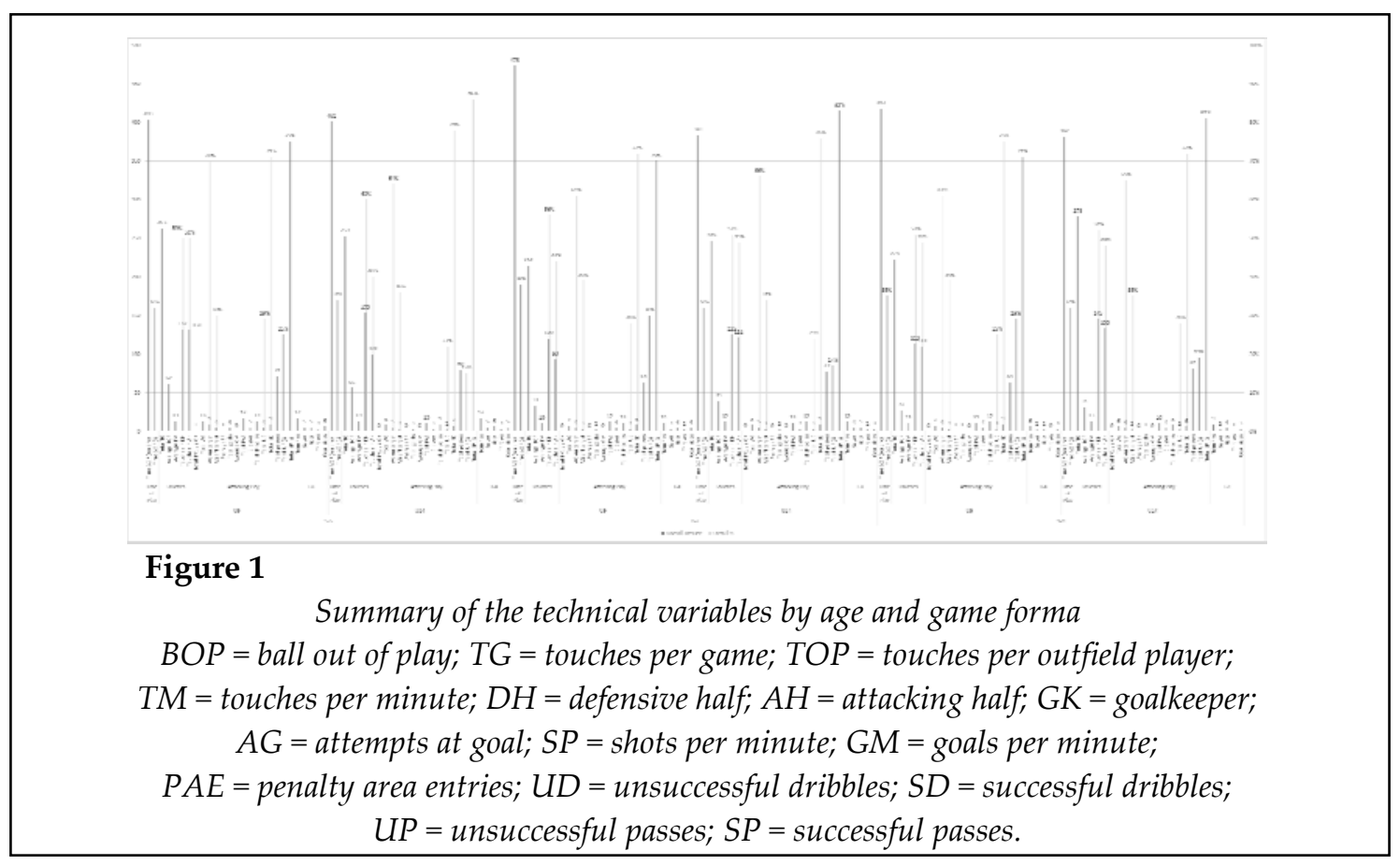




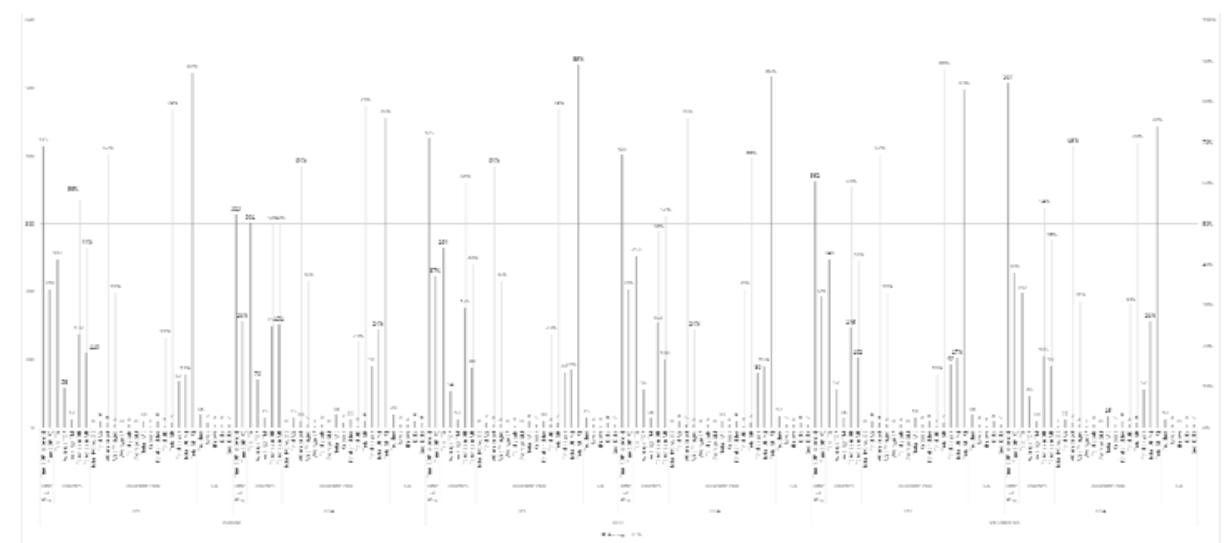

Figure 2

Results of the variables for 5v5. U9 and U14

$B O P=$ ball out of play; $T G=$ touches per game; $T O P=$ touches per outfield player;

$T M=$ touches per minute; $D H=$ defensive half; $A H=$ attacking half; $G K=$ goalkeeper;

$A G=$ attempts at goal; $S P=$ shots per minute; $G M=$ goals per minute;

$P A E=$ penalty area entries; $U D=$ unsuccessful dribbles; $S D=$ successful dribbles;

$U P=$ unsuccessful passes; $S P=$ successful passes

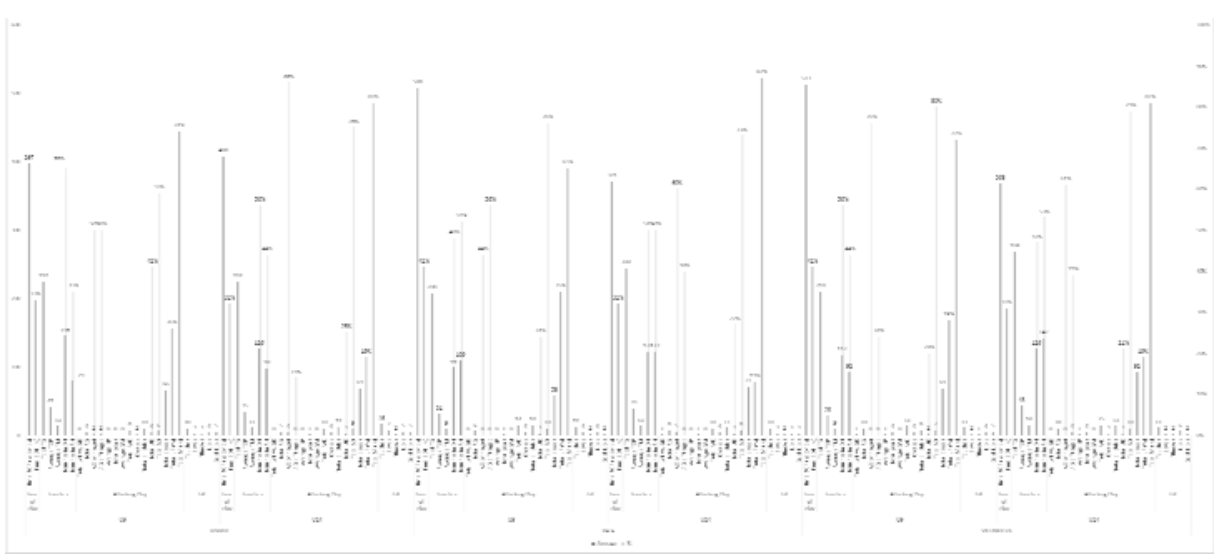

Figure 3

Results of the variables for 7v7, U9 and U14

$B O P=$ ball out of play; $T G=$ touches per game; $T O P=$ touches per outfield player;

$T M=$ touches per minute; $D H=$ defensive half; $A H=$ attacking half; $G K=$ goalkeeper;

$A G=$ attempts at goal; $S P=$ shots per minute; $G M=$ goals per minute;

$P A E=$ penalty area entries; $U D=$ unsuccessful dribbles; $S D=$ successful dribbles;

$U P=$ unsuccessful passes; $S P=$ successful passes 


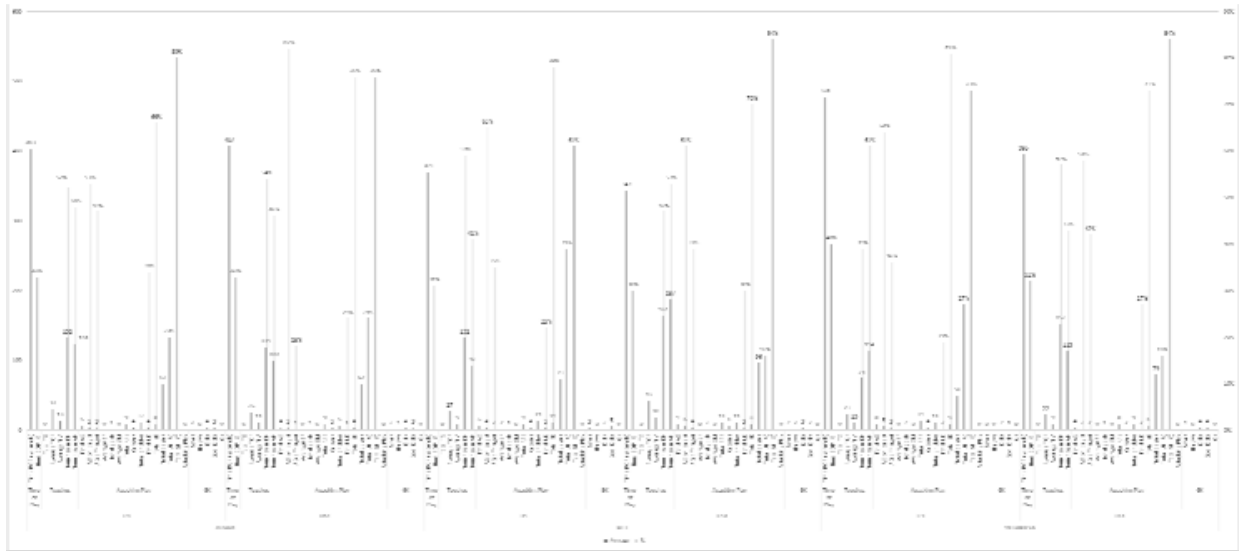

Figure 4

Results of the variables for $9 v 9$. U9 and U14

$B O P=$ ball out of play; $T G=$ touches per game; $T O P=$ touches per outfield player;

$T M=$ touches per minute; $D H=$ defensive half; $A H=$ attacking half; $G K=$ goalkeeper;

$A G=$ attempts at goal; $S P=$ shots per minute; $G M=$ goals per minute;

$P A E=$ penalty area entries; $U D=$ unsuccessful dribbles; $S D=$ successful dribbles;

$U P=$ unsuccessful passes; $S P=$ successful passes

\section{Discussion}

The study showed that there were more touches of the ball and attacking play in the smaller game formats (Sampaio and Maças, 2012); there was a higher frequency among the variables for attacking play in all age groups and playing surfaces (goals, shots on goal and balls entering the penalty area) in the smaller-sided games (5v5 and $7 \mathrm{v} 7$ ) than in the $9 \mathrm{v} 9$ format (Okihara et al., 2004). It should be noted in particular, that the U9 age group playing in the $5 \mathrm{v} 5$ format created more attacking moves and attacks than any other age group and game format, directly influencing the intensity of play (Koklu et al., 2011) and therefore, the learning process during training (Iaia et al., 2009). Furthermore, the main trend when it comes to the number of touches of the ball for outfield players across all age groups and playing surfaces was that the number of touches was significantly higher in $5 \mathrm{v} 5$ and $7 \mathrm{v} 7$ than in 9v9 (Lago and Martín, 2007). The same trend could be observed for the goalkeepers (Di Salvo et al., 2007), with them having a higher number of touches in $5 \mathrm{v} 5$ and $7 \mathrm{v} 7$ than in $9 \mathrm{v} 9$ for all playing surfaces and in both age groups. On the whole, by comparing the levels of attacking play in each format, we can see that the general trend was for the frequency of all variables of attacking play to be higher in the smaller-sided games (5v5 and 7v7) than in the 9v9 format (Jones and Drust, 2007; Tenga et al., 2010).

With regard to playing time and possession, the most obvious trend across the different types of playing surface was that on artificial turf, the ball was out of play considerably longer in the U-9 age group (41\%) than in the U-14 age group (32\%). For the U-9 age group, the ball was out of play for less time on a natural grass surface $37 \%$ for $5 \mathrm{v} 5,32 \%$ for $7 \mathrm{v} 7$ and $30 \%$ for 9v9). Age and physicality had a significant influence on the variables that corresponded to the players' technical, tactical and physical performances (Silvestre et al., 2006); even though the trends listed above were consistent in most of the formats and age groups, we found variations in the technical variables across the various age groups (U-9 and U-14). The ball was out of play in 
the U-9 age group for less time in the $5 \mathrm{v} 5$ format and for more time in the $7 \mathrm{v} 7$ and $9 \mathrm{v} 9$ formats, making play more broken and directly influencing its intensity (Dellal et al., 2008). In the U-14 age group, however, the ball was out of play for less time in the $9 \mathrm{v} 9$ format and for more time in $7 \mathrm{v} 7$. With respect to attempted passes in both the $7 \mathrm{v} 7$ and $9 \mathrm{v} 9$ formats, the U-14 age group tried more passes than the U-9 group, thus following what they had previously learned as well as the demands of the game format (Dellal et al., 2011a). Furthermore, there was a much higher percentage of success across the data collected in the U-14 age group than in the U-9 (87\% compared to $64 \%$ in $7 \mathrm{v} 7$, and $83 \%$ compared to $73 \%$ in $9 \mathrm{v} 9$ ). Although, there was a clear tendency towards greater levels of attacking play in the $5 \mathrm{v} 5$ format than in $9 \mathrm{v} 9$ for both age groups (Hill-Haas et al., 2009), there were more attacking moves in the $9 \mathrm{v} 9$ format among the U-14 players. The variations in the technical variables between the two age groups can be explained by the fact that the U-14 age group is technically more competent than the U-9 group and is more used to competitive situations (Dellal et al., 2011b). Furthermore, the data collected from the U-14 age group show more positive values for surfaces that facilitate passing and building attacking play, such as artificial and natural turf.

Having discussed the most representative values for the technical and tactical moves reflected in different variables of this study, it can be said that all of them are closely interrelated (Myers et al., 2004) and change uniformly depending on the type of the playing surface, game format and age group. Therefore, they cannot be seen as isolated moves but rather as part of a co-evolution. One of the most important goals of any coach is to get his players to develop a high level of technical and tactical ability, because in most cases, it is not the competitor with the most stamina, strength, speed or flexibility who wins, and neither is it the player who is able to give the best technical delivery in terms of biomechanics, but rather it is the athlete who is able to perceive a variety of different situations that occur during a match, analyse them correctly and make the right move technically, assessing his own situation against that of his rival.

\section{Practical applications}

The results of this study show the relevance of reduced spaces in learning how to play football and in training sessions. Players are involved in more decision-making and moves in small-sided formats, which results in a greater volume of these in practice (both in learning and training), in the technical and tactical variables as well as in the physical variables (Reilly and White, 2004). In small-sided soccer, playing systems are not particularly important, especially at an early age. Nevertheless (and bearing in mind the theoretical terms defined above), it can be said that the concepts of tactics and strategy gain special importance in soccer played in reduced spaces given the large number of moves in which players are involved (Leser et al., 2011). All of the factors that influence moves, such as the surface, the number of players and their ability, will quickly vary, which means that it is even more important to consider various choices that players can take and their direct relationship with tactics and strategy. The player, as an indispensable element of the game, is the person who establishes the internal logic of sports, especially team sports (Lames and McGarry, 2007). Therefore, one of the key considerations when organising a small-sided soccer match is choosing a format that gives the players a sense of freedom which encourages their creativity and hence lets them discover various play possibilities (Kelly and Drust, 2009), while being able to manage the spaces according to their technical, anthropometric and physiological characteristics (Gil et al., 2007; Rampinini et al., 2007) and understand both attacking and defensive play and tactical situations.

The various formats of small-sided soccer considered for this study showed an evolution from the smallest to the biggest. Therefore, we could confirm that there is a development in various small-sided soccer formats (from $5 \mathrm{v} 5$ to 9v9) which can be applied and directly transferred to $11 \mathrm{v} 11$ football in a final stage (Dellal et al., 2011c; Owen et al., 2011). If an 11-a-side soccer pitch (approx. $100 \times 70$ meters) is divided into different imaginary spaces (based on lines/positions, pitch areas, duels among players, triangles, etc.), the concept of "reduced spaces" can also be applied to soccer played in these dimensions for a large number of moves. 


\section{Acknowledgements}

The authors thank the players who participated in the study. The study was endorsed by the Fédération Internationale de Football Association (FIFA) and has also been supported by the Royal Spanish Football Federation Association (RFEF). In addition, FIFA donated sports equipment (balls, bibs, cones, markers and mini-goals) to the clubs involved in the study. The authors declare that they have no conflicts of interest related to the contents of the study. No funding from any institution has been granted for this study.

\section{References}

Castellano J, Perea A, Hernández-Mendo A. Analysis of football development across the World Cups. Psicothema, 2008; 20: 928-932

Castellano J, Blanco-Villaseñor A, Álvarez D. Contextual variables and time-motion analysis in soccer. Int J Sports Med, 2011; 32: 415-421

Dellal A, Chamari K, Pintus A, Girard O, Cotte T, Keller D. Heart rate responses during small-sided games and short intermittent running training in elite soccer players: a comparative study. J Strength Cond Res, 2008; 22: 1449-1457

Dellal A, Chamari K, Owen AL, Wong DP, Lago-Penas C, Hill-Haas S. Influence of technical instructions on the physiological and physical demands of small-sided soccer games. Eur J Sport Sci, 2011a; 11: 341-346

Dellal A, Hill-Haas S, Lago-Penas C, Chamari K. Small-sided games in soccer: amateur vs. professional players' physiological responses, physical, and technical activities. J Strength Cond Res, 2011b; 25: 23712381

Dellal A, Owen A, Wong DP, Krustrup P, Van Exsel M, Mallo J. Technical and physical demands of small vs. large sided games in relation to playing position in elite soccer. Hum Movement Sci. In press, 2011c

Di Salvo V, Baron R, Tschan H, Calderon-Montero F, Bachl N, Pigozzi F. Performance characteristics according to playing position in elite soccer. Int J Sports Med, 2007; 28: 222-227

Di Salvo V, Gregson W, Atkinson G, Tordoff P, Drust B. Analysis of high intensity activity in premier league soccer. Int J Sports Med, 2009; 30: 205-212

Federation Internationale de Football Association. Grassroots Manual. Zurich: FIFA Education and Technical Development, 65-69; 2012

Gabbet TJ, Mulvey M. Time-Motion analysis of small sided training games and competition in elite women soccer players. J Strength Cond Res, 2008; 22: 543-552

Gil SM, Gil J, Ruiz F, Irazusta A, Irazusta J. Physiological and Anthropometric Characteristics of Young Soccer Players According to Their Playing Position: Relevance for the Selection Process. J Strength Cond Res, 2007; 21: 438-445

Gréhaigne JF, Godbout P, Zerai Z. How the "rapport de forces" evolves in a soccer match: the dynamics of collective decisions in a complex system. Rev Psicol Dep, 2011; 20: 747-765

Hill-Haas SV, Coutts AJ, Rowsell GJ, Dawson BT. Generic versus small-sided game training in soccer. Int J Sports Med, 2009; 30: 636-642

Iaia FM, Rampinini E, Bangsbo J. High-intensity training in football. Int J Sports Physiol Perf, 2009; 4: 291-306

Jones S, Drust B. Physiological and technical demands of $4 \mathrm{v} 4$ and $8 \mathrm{v} 8$ games in elite youth soccer players. Kinesiology, 2007; 39: 150-156

Kelly D, Drust M. The effect of pitch dimensions on heart rate responses and technical demands of small-sided soccer games in elite players. Research Institute for Sport and Exercise Sciences. Liverpool, UK: John Moores University; 2008 
Kelly D, Drust M. The effect of pitch dimensions on heart rate responses and technical demands of smallsided soccer games in elite players. J Sci Med Sport, 2009; 12: 475-479

Koklu Y, Asci A, Kocak FU, Alemdaroglu U, Dundar U. Comparison of the physiological responses to different small-sided games in elite young soccer players. J Strength Cond Res, 2011; 25: 1522-1528

Lago C, Martín R. Determinants of possession of the ball in soccer. J Sports Sci, 2007; 25: 969-974

Lames M, McGarry T. On the search for reliable performance indicators in game sports. Int J Perf Analysis Sport, 2007; 7: 16

Leser R, Baca A, Ogris G. Local Positioning Systems in (Game) Sports. Sensors, 2011; 11: 9778-9797

McGarry T, Anderson DI, Wallace SA, Hughes MD, Franks IM. Sports Competition as a dynamical selforganizing system. J Sport Sci, 2002; 20: 771-781

Myers ND, Feltz DL, Short SE. Collective efficacy and team performance: A longitudinal study of collegiate football teams. Group Dynamics: Theory, Research, and Practice, 2004; 8: 126-138

Okihara K, Kan A, Shiokawa M, Choi CS, Deguchi T, Matsumoto M, Higashikawa Y. Compactness as a strategy in a soccer game in relation with the change in offence and defense. Part II: Game activity and analysis. J Sports Sci, 2004; 22: 500-520

Owen AL, Wong DP, McKenna M, Dellal A. Heart rate responses and technical comparison between smallvs. large sided games in elite professional soccer. J Strength Cond Res, 2011; 25 2104-2110

Rampinini E, Impellizzeri FM, Castagna C, Abt G, Chamari K, Sassi A, Marcora SM. Factors influencing physiological responses to small-sided soccer games. J Sports Sci, 2007; 25: 659-666

Reilly T, White C. Small-sided games as an alternative to interval-training for soccer players. J Sports Sci, 2004; 22: 559

Sampaio J, Maçãs V. Measuring Football Tactical Behaviour. Int J Sports Med, 2012; 33: 1-7

Silvestre R, Kraemer WJ, West C, Judelson DA, Spiering BA, Vingren JL, Hatfield DL, Anderson JM, Maresh CM. Body composition and physical performance during a National Collegiate Athletic Association Division I men's soccer season. J Strength Cond Res, 2006; 20: 962-970

Tenga A, Holme I, Ronglan LT, Bahr R. Effect of playing tactics on achieving score-box possessions in a random series of team possessions from Norwegian professional soccer matches. J Sports Sci, 2010; 28: 245-255

\section{Corresponding author:}

\section{Jorge Diaz-Cidoncha Garcia}

Affiliation: Fédération Internationale de Football Association (FIFA). Education and Technical Development Department. / National Institute of Physical Education (INEF), Polytechnic University of Madrid. Sports Department.

Mailing Address: Niederdorfstrasse 48. 8001 Zurich. Switzerland.

Telephone number: +41 (0) 793689252 / +41 (0) 432227777

Fax: +41-(0)43-222 7878

Email address: jorge.diaz@fifa.org 